\title{
Mental Health Literacy of Autism Spectrum Disorder in Korea: Recognition, Etiology, Treatment
}

\author{
Soo Jung Rim, Subin Park ${ }^{\bowtie}$, Yeeun Lee, and Chul Eung Kim \\ Clinical Research Center, Mental Health Research Institute, National Center for Mental Health, Seoul, Republic of Korea
}

\begin{abstract}
Objective The objective of this study was to investigate the Korean public's recognition of autism spectrum disorder (ASD), revealing underlying factors regarding perception relative to etiology and treatment of ASD, and examining variables related to those factors.

Methods An online survey was held to investigate mental health literacy (MHL) on ASD of the general public in Korea. A total of 673 adults participated and completed questionnaires on socio-demographic characteristics and if they know someone with ASD. Next, participants were provided with a vignette describing a child with ASD. Only those that recognized there was a problem with the child moved to the next part which asked their perception regarding etiology and treatment of ASD.

Results According to our study, approximately $25 \%$ of participants correctly recognized the child in the vignette as having ASD. Perception regarding etiology and treatment of ASD varied among socio-demographic characteristics. Participants acquainted with someone with ASD and correctly recognized ASD held mixed perception regarding cause and treatment.

Conclusion This study investigated MHL of ASD in Korea. The result reveals there is much room for improvement relative to raising awareness on MHL of ASD. Intervention considering socio-demographic characteristics and acquaintance with ASD are needed.
\end{abstract}

Psychiatry Investig 2019;16(3):213-219

Key Words Autism spectrum disorder, Mental health literacy, South Korea.

\section{INTRODUCTION}

Mental disorders are globally revealing high prevalence rates. According to a meta-analysis, ${ }^{1}$ approximately $30 \%$ of individuals experience a common mental disorder (e.g., depression and anxiety disorder) during their lifetime. Despite high prevalence rate, the general public has little knowledge of mental disorders; the public is unaware of what to do for prevention, avoid seeking help, and do not know how to help those with mental disorders. ${ }^{2}$ This could contribute to approximately $70 \%$ of those with mental disorders not being treated for their disorder. ${ }^{3}$ Accordingly, researchers have concentrated on the general public's perception about psychiatric disorders that guide their perception, management or prevention-

Received: September 12, 2018 Revised: December 9, 2018

Accepted: January 10, 2019

$\triangle$ Correspondence: Subin Park, MD, PhD

Department of Research Planning, Mental Health Research Institute, National Center for Mental Health, 127 Yongmasan-ro, Gwangin-gu, Seoul 04933, Republic of Korea

Tel: +82-2-2204-0108, Fax: +82-2-2204-0280, E-mail: subin-21@hanmail.net (ac) This is an Open Access article distributed under the terms of the Creative Commons Attribution Non-Commercial License (https://creativecommons.org/licenses/bync/4.0) which permits unrestricted non-commercial use, distribution, and reproduction in any medium, provided the original work is properly cited. mental health literacy (MHL). ${ }^{4} \mathrm{MHL}$ is associated with identifying and recognizing specific mental disorders, acknowledging where to collect information regarding mental health, understanding the risk factors and causes of various treatments, and attitudes associated with help seeking behavior. ${ }^{4}$

Autism spectrum disorder (ASD) is a neurodevelopmental disorder with high prevalence rates; globally one in 132 individuals is diagnosed with ASD. ${ }^{5}$ Symptoms include deficiency in communication (e.g., difficulty in understanding non-verbal cues, rendering inappropriate reactions during conversations, difficulty making friends) and dependency on routines and being highly sensitivity to changes in environment (DSM5). Early diagnosis of ASD is critical since it is related to treatment outcomes; the earlier intervention occurs, the better the outcome. ${ }^{6}$ Early intervention is also related to the raising family's acceptance and adjusting to their child's disorder. ${ }^{7}$ A critical factor for early intervention is to recognize symptoms of mental disorders. ${ }^{2,8}$ However, despite a standardized diagnostic criterion the age of being diagnosed with ASD is high; the average age of being diagnosed with ASD in U.S, and Japan was 3.1 and 7.2 , respectively. ${ }^{9.10}$

After recognizing a mental disorder, it is critical to receive 
effective treatment. A key factor that contributes to which treatment to receive is related to the individual's perception on the disorder's etiology. Since ASD is a neurodevelopmental disorder, parents' treatment choices were dependent on their perception of the etiology of ASD; ${ }^{11}$ those with a perception that food allergy were the cause of ASD revealed higher odds of using special diet or vitamins for treatment and those that perceived their mother being ill during pregnancy as the cause had higher odds of using medication. Until now, the exact etiology of ASD has not been identified. Although, currently, the most accepted etiology is genetic factors, there are other suggested factors such as chemicals and nutrition air pollution, pesticides, mercury, and deficiency of vitamin D or fatty acid. ${ }^{12}$ Even parents detached to the child were once regarded as the cause of ASD. ${ }^{13}$ Since there is no exact mechanism known for ASD, perception regarding etiology of ASD could vary among parents and the general public.

Most studies on MHL have focused on mental disorders such as schizophrenia or depression. ${ }^{14-16}$ However, since early diagnosis and intervention are crucial for neurodevelopmental disorders including ASD, ${ }^{17,18}$ this area requires more attention. A review study emphasizes that cultural differences must be considered when studying MHL. ${ }^{19}$ However, studies regarding MHL in Korea are scarce. There were studies of MHL regarding a specific disorder such as schizophrenia 15 or of specific demographic groups such as the elderly $y^{20,21}$ or married immigrant women. ${ }^{22}$ To our knowledge, there is no study that investigated MHL of ASD in Korea. So, we will investigate MHL (recognition and perception about causes and treatment of ASD) and variables related to their perception in Korea. Results from this research will facilitate improving mental health literacy in South Korea.

\section{METHODS}

\section{Participants}

We held an online survey through a consumer panel site (www. invight.co.kr) managed by an online research service company. The site disperses e-mail survey invitations to random respondents included in their register by proportionate allocation according to the population's age distribution in South Korea. Potential respondents participated in at least one survey during the last 12 months. Information regarding our study was provided on the website. A total of 673 respondents (337 males) age 20-64 (M=42.77) were included in the study. All respondents consented to participate in our study by pressing the "participate" button on the screen. This study was approved by the Institutional Review Board of the National Center for Mental Health (No.116271-2017-38).

\section{Materials}

\section{Sociodemographic data}

Information regarding participants' socio-demographic characteristics (age, sex, SES, education, and religion) was collected. Also, we asked if the participant knows someone close to them with ASD (i.e., family member, relative, or friend).

\section{Recognition of ASD}

A vignette describing a three-year-old child manifesting symptoms of ASD was provided. Characteristics of the child were based on diagnostic criteria of ASD based on Diagnostic and Statistical Manual of Mental Disorders (DSM-V) $)^{23}$ and International Classification of Diseases $10^{\text {th }}$ Revision (ICD-10) ${ }^{24}$ was provided. After reading the vignette, participants were asked "In your opinion, is there anything wrong with the child?" Only those that answered "yes" proceeded to the next question. The next question was an open question and asked participants "If there is, what do you think is wrong with the child?"

\section{Perception of ASD}

Then participants proceeded to the next part of the survey. In this part of the survey, participants were informed that the child described in the vignette had ASD with a brief description of ASD. Then participants answered a 26-item questionnaire of perceptions regarding ASD etiology and treatments. The questionnaire was a modified version from a previous study. ${ }^{25}$ The original questionnaire contained 24 items. We have included two items (i.e., "Vaccine can cause autism" and "Being excessively exposed to television/internet/smartphone can cause autism") which could be related to beliefs or perception general public holds regarding the etiology of ASD. Participants rated how much they agreed for each statement on a 7point Likert scale ranging from 1 (disagree strongly) to 7 (agree strongly).

\section{Statistical analysis}

First, we conducted a factor analysis to identify the underlying structure of participants' perception regarding causes and treatments of ASD. Only factors with eigenvalue higher than 1 and items with loadings higher than $0.4^{26}$ were included. After investigating underlying factors, we performed a $t$ test or ANOVA to investigate if mean scores for each factor differed by socio-demographic variables. Then, Multiple Regression test was done to assess association between perception about causes and treatment and socio-demographic variables. All statistical analysis was done with SPSS 21.0 (IBM Corp., Armonk, NY, USA). Moreover, p-value less than 0.05 were regarded as significant. 


\section{RESULTS}

\section{Recognition of ASD}

The frequency of answers that participants provided regarding the diagnosis of the child is provided in Table 1. There were 169 responses that correctly recognized the child in the vignette as with $\mathrm{ASD}$. The next most frequent responses were 'don't know' (58 responses) followed by language/communication disorder (52 responses), neat freak (46 responses), and developmental problem/disorder (42 responses).

\section{Means and factor loadings for questionnaire items on ASD etiology and treatment}

Table 2 displays the mean score for each 24 items with factor analysis (Varimax rotated) results. The five factors accounted for $61.19 \%$ of variance in total. The first factor comprised items 1, 5, 6, 7, 8, 9, 15, 16, 24 labeled as 'parenting and behavioral' and accounted for $32.57 \%$ of the variance. The second factor labeled 'environmental exposure' comprised items 2, $12,13,23,25,26$, accounted for $11.50 \%$ of variance. The third factor including items 14,17, 19 were labeled as 'will and faith' and accounted for $7.67 \%$ of variance. The fourth factor labeled 'brain abnormality and pregnancy' comprised items 4, 20, 22 that accounted for $5.14 \%$ of variance. The fifth item labeled 'genetic and drug' was comprised of items 10, 11, 18 and accounted for $4.32 \%$ of variance.

\section{Perception on ASD's etiology and treatment factors by participant characteristics}

Table 3 shows the difference of perception on ASD's etiology and treatment factors by socio-demographic characteristics, having acquaintance with ASD, and ASD recognition. Men had higher 'will and faith' perception than women. Post-hoc comparisons using Bonferroni showed that participants in their 20 's had a higher perception in 'brain abnormality' factor compared to the 30s $(\mathrm{p}<0.01), 40 \mathrm{~s}(\mathrm{p}=0.03)$, and 60s $(\mathrm{p}=0.03)$. Moreover, respondents with income higher than 50,000,000 won revealed higher perception in 'parenting and behavioral' factors compared to those with income less than 20,000,000 won ( $\mathrm{p}=0.04)$. Religious participants revealed a higher belief in 'parenting and behavioral' and 'will and faith' factors. Respondents that knew someone with ASD revealed lower perception on 'will and faith' and 'genetic and drug.' Those that recognized the child in the vignette as with ASD revealed lower perception in the 'will and faith' factor.

\section{Variables associated with etiology and treatment factors of ASD}

Table 4 shows the result from multiple regression analysis regarding variables associated with perception on etiology and
Table 1. Frequency of diagnoses in ASD case

\begin{tabular}{|c|c|}
\hline Diagnosis & Frequency (\%) \\
\hline Autism & $169(29.86)$ \\
\hline Don't know & $58(10.25)$ \\
\hline Language/communication disorder & $52(9.19)$ \\
\hline Neat freak & $46(8.13)$ \\
\hline Developmental problem/disorder & $42(7.42)$ \\
\hline Obsession & $30(5.30)$ \\
\hline Attention problem & $20(3.53)$ \\
\hline Emotional problem/emotional instability & $14(2.47)$ \\
\hline Mental disorder/problem & $13(2.30)$ \\
\hline Intellectual problem/disability & $12(2.12)$ \\
\hline Anxiety & $11(1.94)$ \\
\hline Social problem/Lack of sociality & $10(1.77)$ \\
\hline Behavioral problem & $8(1.41)$ \\
\hline Paranoia & $8(1.41)$ \\
\hline Lack of affection & $7(1.24)$ \\
\hline Dawn syndrome & $6(1.06)$ \\
\hline Eye contact problem & $5(0.88)$ \\
\hline Brain problem & $4(0.71)$ \\
\hline Cognitive/thought disorder & $4(0.71)$ \\
\hline Deficit/disorder & $4(0.71)$ \\
\hline Hypersensitive & $4(0.71)$ \\
\hline Parental problem & $4(0.71)$ \\
\hline Anger control & $3(0.53)$ \\
\hline Developmental delay & $3(0.53)$ \\
\hline Overall problem & $3(0.53)$ \\
\hline Personality problem (e.g., timid) & $3(0.53)$ \\
\hline Schizophrenia & $3(0.53)$ \\
\hline Tic/Tourette disorder & $3(0.53)$ \\
\hline Abnormal & $2(0.35)$ \\
\hline Neurological problem & $2(0.35)$ \\
\hline Self-focused & $2(0.35)$ \\
\hline Asperger syndrome & $1(0.18)$ \\
\hline Cerebral palsy & $1(0.18)$ \\
\hline Compulsive disorder & $1(0.18)$ \\
\hline Cross-eyed & $1(0.18)$ \\
\hline Genetic problem & $1(0.18)$ \\
\hline Lack of empathic ability & $1(0.18)$ \\
\hline Lack of purpose & $1(0.18)$ \\
\hline Panic disorder & $1(0.18)$ \\
\hline Servant syndrome & $1(0.18)$ \\
\hline Unpredictable & $1(0.18)$ \\
\hline ADHD & $1(0.18)$ \\
\hline
\end{tabular}

Multiple responses were allowed for each person. ADHD: attention-deficit hyperactivity disorder 
Table 2. Means and factor loadings for questionnaire items on ASD etiology and treatment

\begin{tabular}{|c|c|c|c|c|}
\hline Factor and items & Loading & $\begin{array}{l}\text { Eigen } \\
\text { value }\end{array}$ & $\begin{array}{c}\text { Variance } \\
\text { accounted for }(\%)\end{array}$ & $\begin{array}{l}\text { Mean } \\
(\mathrm{SD})\end{array}$ \\
\hline Parenting and behavioral & & 7.82 & 32.57 & \\
\hline 7. Providing a warm and loving environment can help people overcome autism. & 0.828 & & & $4.92(1.27)$ \\
\hline $\begin{array}{l}\text { 6. Autism can be best helped by encouraging suffers to interact with others who } \\
\text { are 'normal'. }\end{array}$ & 0.678 & & & $4.83(1.31)$ \\
\hline 1. Autistics can be helped to improve their behavior through one-to-one therapy. & 0.658 & & & $4.68(1.48)$ \\
\hline 9. Having a 'bad upbringing' causes autism. & 0.628 & & & $4.62(1.37)$ \\
\hline 24. Treatment of autism is easier if the sufferer really wants to get better. & 0.619 & & & $4.76(1.34)$ \\
\hline 5. Traumatic experience very early in life can cause autism. & 0.618 & & & $4.69(1.30)$ \\
\hline 8. Having emotionally cold parents often causes autism. & 0.614 & & & $4.39(1.41)$ \\
\hline 15. Giving 'rewards' for 'normal' behavior can reduce autistic behavior. & 0.607 & & & $4.33(1.27)$ \\
\hline 16. Cold and unloving homes are a frequent cause of autism. & 0.563 & & & $4.35(1.44)$ \\
\hline Environmental exposure (diet, chemical, etc.) & & 2.76 & 11.50 & \\
\hline 13. Eating certain types of food can worsen autistic behavior. & 0.782 & & & $3.69(1.41)$ \\
\hline 12. Changes in diet can be very efficient in treating autism. & 0.716 & & & $3.81(1.35)$ \\
\hline 23. Allergies to some foods can cause autism. & 0.715 & & & $3.46(1.40)$ \\
\hline 25. Vaccine can cause autism. & 0.613 & & & $3.66(1.29)$ \\
\hline 26. Being excessively exposed to television/internet/smartphone can cause autism. & 0.609 & & & $3.89(1.43)$ \\
\hline 2. A chemical imbalance is the main cause of autism. & 0.556 & & & $4.03(1.30)$ \\
\hline Will and faith & & 1.84 & 7.67 & \\
\hline 17. Punishing 'strange' and inappropriate behavior can reduce autistic behavior. & 0.658 & & & $3.30(1.48)$ \\
\hline 14. Whether a person with autism gets better may simply depend on luck. & 0.638 & & & $3.20(1.48)$ \\
\hline 19. A belief in God can help a person overcome autism. & 0.628 & & & $3.29(1.69)$ \\
\hline Brain abnormality and pregnancy & & 1.23 & 5.14 & \\
\hline 22. The main cause of autism is brain abnormality. & 0.839 & & & $4.75(1.19)$ \\
\hline 4. Brain abnormalities are the main cause of autism. & 0.783 & & & $4.99(1.18)$ \\
\hline 20. Complications during pregnancy can cause autism. & 0.503 & & & $4.09(1.33)$ \\
\hline Genetic and drug & & 1.04 & 4.32 & \\
\hline 10. The best way to treat autism is using appropriately prescribed drugs. & 0.717 & & & $4.13(1.34)$ \\
\hline 18. Drugs are an effective way of treating autism. & 0.699 & & & $4.23(1.33)$ \\
\hline 11. Autism is caused essentially by genetic factor. & 0.427 & & & $3.93(1.37)$ \\
\hline
\end{tabular}

ASD: autism spectrum disorder, SD: standard deviation

treatment factors of ASD. Men were associated with 'will and faith' factor. Age was negatively associated with 'brain abnormality' factor. Higher income was associated with 'parenting and behavioral' and 'brain' factors and negatively associated with 'will and faith' factor. Knowing someone with ASD and correctly recognizing ASD was negatively associated with 'will and faith' and 'genetic and drug' factors.

\section{DISCUSSION}

This study investigated MHL of ASD of the public in South Korea. According to our results, recognition of ASD among the public in Korea is relatively low; approximately $25 \%$ of participants correctly recognized the child in the vignette as with ASD. This rate is lower than China ${ }^{27}$ or Japan ${ }^{28}$ that reveals a recognition rate of $57.8 \%$ and $45.8 \%$, respectively. The next most frequent responses were 'don't know' followed by 'language/communication disorder', 'neat freak', and 'developmental problem/disorder'. Previous cross-cultural study ${ }^{29}$ regarding MHL found that there was a difference between Asia countries in terms of ability to recognize mental illnesses even though sharing a similar culture. South Korea also has low rate in recognizing and identifying other mental disorders such as schizophrenia and obsessive compulsive disorder. ${ }^{29}$ Our study 
Table 3. Difference of perceptions on ASD's etiology and treatment factors by socio-demographic variables and ASD literacy

\begin{tabular}{|c|c|c|c|c|c|c|c|c|c|c|}
\hline & \multicolumn{2}{|c|}{$\begin{array}{c}\text { Parenting and } \\
\text { behavioral }\end{array}$} & \multicolumn{2}{|c|}{ Will and faith } & \multicolumn{2}{|c|}{ Brain abnormality } & \multicolumn{2}{|c|}{ Diet and chemical } & \multicolumn{2}{|c|}{ Genetic and drug } \\
\hline & $\mathrm{M}(\mathrm{SD})$ & $\mathrm{t} / \mathrm{F}$ & $\mathrm{M}(\mathrm{SD})$ & $\mathrm{t} / \mathrm{F}$ & $\mathrm{M}(\mathrm{SD})$ & $\mathrm{t} / \mathrm{F}$ & $\mathrm{M}(\mathrm{SD})$ & $t / F$ & $\mathrm{M}(\mathrm{SD})$ & $\mathrm{t} / \mathrm{F}$ \\
\hline Sex & & 0.75 & & $2.03^{*}$ & & 0.43 & & 0.03 & & 1.17 \\
\hline Men & 4.62 & & 3.36 & & 4.63 & & 3.75 & & 4.14 & \\
\hline Women & 4.62 & & 3.17 & & 4.59 & & 3.76 & & 4.04 & \\
\hline Age & & 1.69 & & 1.51 & & $4.88^{* *}$ & & 2.30 & & 1.21 \\
\hline $20-29$ & 4.86 & & 3.44 & & 4.86 & & 3.72 & & 4.19 & \\
\hline $30-39$ & 4.44 & & 3.16 & & 4.44 & & 3.56 & & 4.04 & \\
\hline $40-49$ & 4.54 & & 3.25 & & 4.54 & & 3.87 & & 4.04 & \\
\hline $50-59$ & 4.71 & & 3.17 & & 4.71 & & 3.86 & & 4.18 & \\
\hline $60^{-}$ & 4.35 & & 3.41 & & 4.35 & & 3.68 & & 3.87 & \\
\hline Education level & & 0.13 & & 0.73 & & 0.52 & & 1.51 & & 1.93 \\
\hline High school & 4.59 & & 3.14 & & 4.55 & & 3.68 & & 3.95 & \\
\hline College ( $2-3$ years) & 4.60 & & 3.33 & & 4.67 & & 3.66 & & 4.01 & \\
\hline University & 4.63 & & 3.27 & & 4.60 & & 3.81 & & 4.16 & \\
\hline Income Level & & $3.52^{*}$ & & 1.66 & & 2.84 & & 0.10 & & 0.60 \\
\hline Under $20,000,000$ Won & 4.43 & & 3.41 & & 4.53 & & 3.71 & & 4.14 & \\
\hline $20,000,000-49,000,000$ Won & 4.58 & & 3.30 & & 4.54 & & 3.76 & & 4.05 & \\
\hline $50,000,000-$ Won & 4.73 & & 3.17 & & 4.72 & & 3.76 & & 4.14 & \\
\hline Religion & & $2.38^{*}$ & & $2.20^{*}$ & & 1.15 & & 1.78 & & 0.56 \\
\hline Yes & 4.70 & & 3.36 & & 4.65 & & 3.83 & & 4.12 & \\
\hline No & 4.53 & & 3.16 & & 4.57 & & 3.68 & & 4.07 & \\
\hline ASD acquaintance & & 0.28 & & $2.48^{*}$ & & 0.62 & & 1.38 & & $2.37^{*}$ \\
\hline Yes & 4.64 & & 3.00 & & 4.56 & & 3.63 & & 3.86 & \\
\hline No & 4.61 & & 3.31 & & 4.62 & & 3.78 & & 4.14 & \\
\hline ASD literacy & & 0.81 & & $3.86^{* *}$ & & 0.68 & & 1.19 & & 1.93 \\
\hline Yes & 4.57 & & 2.96 & & 4.57 & & 3.67 & & 3.95 & \\
\hline No & 4.64 & & 3.36 & & 4.63 & & 3.78 & & 4.14 & \\
\hline
\end{tabular}

${ }^{*} \mathrm{p}<0.05,{ }^{* *} \mathrm{p}<0.01$. ASD: autism spectrum disorder

shows that improvement is needed in public recognition of highly-stigmatized mental disorders, particularly ASD, in South Korea. Since recognition and awareness are crucial in management and care, ${ }^{2}$ there must be intervention to promote awareness of ASD in Korea.

Factor analysis revealed five factors for etiology and treatment of ASD that are 'parenting and behavioral,' 'will and faith', 'brain abnormality and pregnancy,' 'environmental exposure,' and 'genetic and drug' factors. These factors are in line with a previous study's ${ }^{25}$ factors that were 'psychogenic and external,' 'pregnancy and environmental treatment,' 'genes and drugs,' 'diet,' and 'brain abnormalities.' Other studies did not perform a factor analysis but studied the cause for ASD by studying similar themes. For example, Mitchell and Locke ${ }^{30}$ divided their factors of the cause for autism as follows: genetic, neurologi- cal, environmental exposure, mental illness, vaccinations, nutrition issues during pregnancy, dietary or nutrition deficiencies, family, drugs, and parenting. A study from Japan ${ }^{28}$ divided their factors of etiology by stress, genetics, temperament, upbringing, complications during birth, brain abnormality, social environment, no particular cause.

Perception of the public in South Korea regarding ASD's etiology and treatment varied among socio-demographic variables, recognition of ASD, and knowing someone (family, relative, or friend) with ASD. Men revealed higher perception on the 'will and faith' factor. Multiple regression analysis also revealed an association with men and the 'will and faith' factor. This is compatible with a previous study ${ }^{28}$ revealing that women have more accurate information on ASD. This could be attributable to women being more engaged in child bearing in 
Table 4. Results of multiple regression analysis of each variable to etiology and treatment factors of ASD

\begin{tabular}{|c|c|c|c|c|c|c|c|c|c|c|}
\hline \multirow[t]{2}{*}{ Variables } & \multicolumn{2}{|c|}{$\begin{array}{c}\text { Parenting and } \\
\text { behavioral }\end{array}$} & \multicolumn{2}{|c|}{ Will and faith } & \multicolumn{2}{|c|}{ Brain abnormality } & \multicolumn{2}{|c|}{ Diet and chemical } & \multicolumn{2}{|c|}{ Genetic and drug } \\
\hline & B & $\mathrm{t}$ & B & $\mathrm{t}$ & B & $\mathrm{t}$ & B & $\mathrm{t}$ & B & $\mathrm{t}$ \\
\hline Sex $($ male $=0)$ & -0.001 & -0.016 & -0.185 & $-2.069^{*}$ & -0.035 & -0.461 & 0.013 & 0.158 & -0.090 & -1.082 \\
\hline Age (per 10 years) & 0.045 & 1.443 & -0.042 & -1.114 & -0.070 & $-2.163^{*}$ & 0.045 & 1.299 & -0.025 & -0.692 \\
\hline Education & -0.007 & -0.139 & 0.055 & 0.881 & -0.025 & -0.477 & 0.083 & 1.459 & 0.111 & 1.888 \\
\hline Income & 0.134 & $2.344^{*}$ & -0.122 & $-1.750^{*}$ & 0.143 & $2.403^{*}$ & -0.007 & -0.112 & 0.020 & 0.304 \\
\hline Religion $(\mathrm{no}=0$ ) & 0.142 & 1.902 & 0.220 & 2.410 & 0.113 & 1.464 & 0.119 & 1.428 & 0.047 & 0.546 \\
\hline ASD acquaintance $(\mathrm{no}=0)$ & 0.007 & 0.067 & -0.306 & $-2.482^{*}$ & -0.059 & -0.563 & -0.185 & -1.647 & -0.273 & $-2.372^{*}$ \\
\hline ASD literacy $(\mathrm{no}=0)$ & -0.068 & -0.810 & -0.415 & $-4.021^{* *}$ & -0.067 & -0.766 & -0.115 & -1.223 & -0.207 & $-2.148^{*}$ \\
\hline
\end{tabular}

All variables are concurrently entered in multiple linear analyses. ${ }^{*} \mathrm{p}<0.05,{ }^{*} \mathrm{p}<0.001$. ASD: autism spectrum disorder

Korean society ${ }^{31}$ and so they may have more accurate knowledge regarding child development.

According to ANOVA and multiple regression analysis results, younger respondents were associated with 'brain abnormality and pregnancy' factor. A previous study $y^{32}$ from Australia reveals that there are age differences in MHL regarding depression and schizophrenia; elderly were less accurate on recognizing mental disorders and they thought character weakness could be the cause for schizophrenia. Conversely, a study conducted in Japan regarding MHL of $\mathrm{ASD}^{28}$ revealed no generation difference between perception of 'brain abnormality' as the cause of ASD; all generations consider 'brain abnormality' as the main cause of ASD. Jeon and Furnham ${ }^{29}$ revealed differences between recognizing a mental disorder varies within countries in Asia. Our study reveals that there are cultural differences between perception regarding etiologies of ASD.

Respondents with higher income had a higher perception of 'parenting and behavioral' factors than those with lower income. According to multiple regression analysis, higher income was associated with 'parenting and behavioral' and 'brain abnormality and pregnancy' factors and negatively associated with 'will and faith' factors. Results are somewhat consistent with a previous study ${ }^{33,34}$ revealing those with lower income generally manifesting discrepancy in understanding ASD. For example, those with lower income considered parenting as the cause for autism, are less likely to consult a doctor for help, and are more optimistic that there are treatments for autism. However, it seems that those with higher income in Korea also hold perceptions regarding 'parenting and behavioral' factors. This reveals that regardless of income level there is room for development on MHL of ASD however focusing on different aspects.

Those belonging to a religion had a higher perception on 'parenting and behavioral' and 'will and faith' factors compared to those without religion. This is compatible with a previous study ${ }^{25}$ that revealed individuals with religion holding percep- tions on environmental factors (e.g., providing a warm and loving environment can enable people to overcome autism) regarding ASD. This reveals that those with religion hold an optimistic view regarding treatment of ASD.

Respondents that know someone with ASD revealed lower perception on 'will and faith' and 'genetic and drug' factors. Multiple regression revealed a negative association between acquaintance with someone that has ASD and 'genetic and drug' and 'will and faith' factors. This result is in line with a study $y^{34}$ that revealed parents holding mixed perceptions on etiology of their child's ASD; genetic cause was the leading reason that parents perceived but at the same time, parents held perceptions on exposure causes. The predominant etiology of ASD is currently lead by genetic factors. However, ASD is a neurodevelopmental disorder that has no clear etiology and no treatment for cure. As a consequence, parents are confronted with conflicting information about treatment of ASD. ${ }^{35}$

Respondents that correctly recognized the child in the vignette as with ASD held lower perception on the 'will and faith' factor compared to those that incorrectly recognized the child. Regression analysis revealed that recognition of ASD was negatively associated with 'will and faith' and 'genetic and drug' factors. Furnham and Buck ${ }^{25}$ revealed that interest in mental illness was associated with genes and drugs factor inconsistent with our result. This affirms that respondents capable of recognizing ASD in Korea have mixed perceptions of the cause or treatment of ASD. This implies that more emphasis is needed on education towards the public about the cause and treatment for ASD.

This study had several limitations. First, due to the crosssectional design of this study, we cannot assume causal relationships between socio-demographic variables, knowing someone with ASD, and recognition of ASD with causal and treatment perceptions of ASD. Second, since our study was based on a self-administered questionnaire, there may have been a reporting bias. 
Despite limitations mentioned above, this study is the first that systematically investigated MHL of the public in Korea on ASD. Overall, the MHL of ASD in Korea is low and needs improvement. Perception of the etiology and treatment of ASD varied depending on socio-demographic variables, recognition of ASD and knowing a person with ASD. Promotion of public literacy about ASD considering socio-demographic characteristics and acquaintance with ASD are needed. Future studies using a larger representative sample of Koreans are needed to generalize our findings.

\section{Acknowledgments}

This work was supported by the National Center for Mental Health, Republic of Korea (grant number R2018-A).

\section{REFERENCES}

1. Steel Z, Marnane C, Iranpour C, Chey T, Jackson JW, Patel V, Silove D. The global prevalence of common mental disorders: a systematic review and meta-analysis 1980-2013. Int J Epidemiol 2014;43:476-493.

2. Jorm AF. Mental health literacy: empowering the community to take action for better mental health. Am Psychol 2012;67:331-243.

3. Thorincroft G. Most people with mental illness are not treated. Lancet 2007;370:807-808

4. Jorm AF, Korten AE, Jacomb PA, Christensen H, Rodgers B, Pollitt P. Public beliefs about causes and risk factors for depression and schizophrenia. Soc Psychiatry Psychiatr Epidemiol 1997;32:143-148.

5. Baxter AJ, Brugha TS, Erskine HE, Scheurer RW, Scott JG. The epidemiology and global burden of autism spectrum disorders. Psychol Med 2015;45:601-613.

6. Klin A, Klaiman C, Jones W. Reducing age of autism diagnosis: developmental social neuroscience meets public health challenge. Rev Neurol 2015;60:S3-S11.

7. Powers MD. Early Intervention for Children with Autism. In: Berkell DE, Editor. Autism: Identification, Education and Treatment. Hillsdale, NJ: Lawrence Erlbaum, 1992, p.225-252.

8. Gulliver A, Griffiths KM, Christensen H. Perceived barriers and facilitators to mental health help-seeking in young people: a systematic review. BMC Psychiatry 2010;10:113.

9. Mandell DS, Novak M, Zubritsky C. Factors associated with age of diagnosis among children with autism spectrum disorders. Pediatrics 2005;116:1480-1486.

10. Kurasawa S, Tateyama K, Iwanaga R, Ohtoshi T, Nakatani K, Yokoi K. The age at diagnosis of autism spectrum disorder in children in Japan. Int J Pediatr 2018:7;2018:5374725.

11. Dardennes RM, Al Anbar NN, Prado-Netto A, Kaye K, Contejean Y, Al Anbar NN. Treating the cause of illness rather than the symptoms: parental causal beliefs and treatment choices in autism spectrum disorder. Res Dev Disabil 2011;32:1137-1146.

12. Fujiwara T, Morisaki N, Honda Y, Sampei M, Tani Y. Chemicals, nutrition, and autism spectrum disorder: a mini-review. Front Neurosci 2016; 10:1-7.

13. Bettelheim B. The empty fortress: Infantile autism and the birth of the self. New York: USA Free Press; 1967.

14. Angermeyer MC, Dietrich S. Public beliefs about and attitudes towards people with mental illness: a review of population studies. Acta Psychi- atr Scand 2006;113:163-179.

15. Park S, Lee M, Furnham A, Jeon M, Ko Y. Lay beliefs about the causes and cures of schizophrenia. Int J Soc Psychiatry 2017;63:518-524.

16. Lauber C, Carlos N, Rössler W. Lay beliefs about treatments for people with mental illness and their implications for antistigma strategies. Can J Psychiatry 2005;50:745-752.

17. Fernell E, Gillberg C. Autism spectrum disorder diagnoses in Stockholm preschoolers. Res Dev Disabil 2010;31:680-685.

18. Yoo H. Early detection and intervention of autism spectrum disorder. Hanyang Med Rev 2016;36:4-10.

19. Altweck L, Marshall TC, Ferenczi N, Lefringhausen K. Mental health literacy: a cross-cultural approach to knowledge and beliefs about depression, schizophrenia and generalized anxiety disorder. Front Psychol 2015;6:1272.

20. Lee EJ, Lee HY, Chung S. Age differences in health literacy: do younger Korean adults have a higher level of health literacy than older Korean adults? Health Soc Work 2017;42:133-141.

21. Kim YS, Rhee G, Lee HY, Park BH, Sharratt ML. Mental health literacy as a mediator in use of mental health services among older korean adults. Int Psychogeriatr 2017;29:269-279.

22. Choi Y. Effects of a program to improve mental health literacy for married immigrant women in Korea. Arch Psychiatr Nurs 2017;31:394-398.

23. American Psychiatric Association. Diagnostic and Statistical Manual of Mental Disorders. Washington, DC: American Psychiatric Association Publishing; 2013.

24. World Health Organization: The ICD-10 Classification of Mental and Behavioural Disorders: Clinical Descriptions and Diagnostic Guidelines. Geneva: World Health Organization; 1992.

25. Furnham A, Buck C. A comparison of lay-beliefs about autism and obsessive-compulsive disorder. Int J Soc Psychiatry 2003;49:287-307.

26. Kaiser $\mathrm{H}$. The application of electronic computers to factor analysis. Educ Psychol Meas 1960;20:141-151.

27. Wang J, Zhou X, Xia W, Sun C, Wu L, Wang J. Autism awareness and attitudes towards treatment in caregivers of children aged 3-6 years in Harbin, China. Soc Psychiatry Psychiatr Epidemiol 2012;47:1301-1308.

28. Koyama T, Tachimori H, Sawamura K, Koyama A, Naganuma Y, Makino $\mathrm{H}$, et al. Mental health literacy of autism spectrum disorders in the Japanese general population. Soc Psychiatry Psychiatr Epidemiol 2009; 44:651-657.

29. Jeon M, Furnham A. Mental health literacy in South Korea. Int J Cult Ment Health 2017;10:353-366.

30. Mitchell GE, Locke KD. Lay beliefs about autism spectrum disorder among the general public and childcare providers. Autism 2015;19:553561.

31. Tsuya NO, Bumpass LL, Kim M. Gender, employment, and housework in Japan, South Korea, and the United States. Rev Popul Soc Policy 2000; 9:195-220.

32. Farrer L, Leach L, Griffiths KM, Christensen H, Jorm AF. Age differences in mental health literacy. BMC Public Health 2008;8:125.

33. Holt JM, Christensen KM. Utahns' understanding of autism spectrum disorder. Diabil Health J 2013;6:52-62.

34. Zuckerman KE, Lindly OJ, Sinche B. Parent beliefs about the causes of learning and developmental problems among children with autism spectrum disorder: results from a national survey. Am J Intellect Dev Disabil 2016;121:432-447.

35. Mandell DS, Zubritsky C, Novak M. A Services Research Perspective on Autism. Paper presented at: American Public Health Association 132nd Annual Meeting and Exposition; Washington, DC; 2004. 